\title{
PENEPMA: A Useful Tool in Intermetallic Phase Identification Along the Joint Interface of Al-Mg Dissimilar Metal Friction Stir Welds
}

\author{
V. Firouzdor ${ }^{1}$, J. H. Fournelle ${ }^{2}$, S. Kou ${ }^{1}$ \\ 1. Department of Materials Science and Engineering, University of Wisconsin, Madison \\ 2.Department of Geoscience, University of Wisconsin, Madison
}

Intermetallic compounds (IMCs) form during friction stir welding (FSW) of Al-to-Mg dissimilar metal joints (Fig 1). $\mathrm{Al}_{3} \mathrm{Mg}_{2}$ and $\mathrm{Al}_{12} \mathrm{Mg}_{17}$ are the two major IMCs of the Al-Mg system. These two IMCs can react with either $\mathrm{Al}$ or $\mathrm{Mg}$ through two separate eutectic reactions and form liquid during welding at 450 or $437{ }^{\circ} \mathrm{C}$ which is below the melting points of $\mathrm{Al}$ and $\mathrm{Mg}$. Liquation during solid state welding process of FSW can deteriorate the joint properties; identification of liquation process and IMCs is critical. A new etching procedure [1] can clearly reveal the joint and associated IMCs, with different color contrast to distinguish the phases (Fig 1) The presence of both $\mathrm{Al}_{3} \mathrm{Mg}_{2}$ and $\mathrm{Al}_{12} \mathrm{Mg}_{17}$ IMCs has been confirmed by using X-ray diffraction and TEM methods (Fig 2 and 3). However, for complete phase identification, electron probe microanalysis (EPMA) by WDS is required to fully identify the in situ chemical composition of IMCs. Experimental data was acquired with UW Madison SX51 operated at $15 \mathrm{kV}$ on polished (non-etched) surfaces. Lower kV was not possible as no BSE contrast was usable for locating the regions of interest.

Unfortunately, the small size ( $<2 \mu \mathrm{m}$ width) of the IMCs makes traditional EPMA difficult due to both excitation by the electron beam of neighboring materials (Fig. 4) and secondary fluorescence (SF) of neighboring materials by characteristic (here, mainly Al K $\alpha$ ) and continuum X-rays. The Andersen-Hasler range for $\mathrm{Mg} \mathrm{Ka}$ is 2.2 microns. Typically EPMA of small phases surrounded by other phases, yields totals greater than $100 \mathrm{wt} \%$ (Table 1). Fortunately, a powerful Monte Carlo simulation program has been developed and distributed to the microanalytical community which can help predict the extent of SF. PENEPMA, based upon the PENELOPE code [2] has been shown to correctly predict the extent of SF in EPMA [3]. During a simulation run, all electrons and photons are followed, and thus evaluating SF is possible. To be able to rigorously evaluate the possible extent of SF, multiple simulations of a modeled geometry similar to the natural ones were run $(1 \mu \mathrm{m}$ wide $\mathrm{x}$ $40 \mu \mathrm{m}$ long x $100 \mu \mathrm{m}$ deep), simulated K-ratios generated, and \% of SF in the total x-ray intensity calculated. Table 2 shows the extent of SF in both the modeled standards ( $1 \mathrm{~cm}$ radius) and the very small IMC: (1) there is no difference in Al Ka SF between the $6061 \mathrm{Al}$ standard and unknown -$\sim 1.4 \%$ of total $\mathrm{x}$-ray intensity, whereas (2) there is noticeably more $\mathrm{Mg} \mathrm{K \alpha}$ SF in IMC (3\%) compared to that in the AZ31B Mg standard (1.7\%). (Simulation errors are max of 1-5\% relative). The ultimate goal is to see if EPMA can yield valid compositional data for the $\mathrm{Al}_{3} \mathrm{Mg}_{2}$ phase. To accomplish that, we compare the experimental K-ratios with those produced from the PENEPMA runs, shown in Table 1. The results are close to the values given in the published phase diagram (Figure 3a). Research is continuing running PENEPMA using different sizes of IMCs. Additionally, melt droplets containing large $(>5 \mu \mathrm{m})$ phases of both $\mathrm{Al}_{3} \mathrm{Mg}_{2}$ and $\mathrm{Al}_{12} \mathrm{Mg}_{17}$ have been found, with good EPMA results, which present a new opportunity to evaluate the performance of PENEPMA for these compositions and geometries.

[1] V.Firouzdor, S.Kou, Welding Journal, 88 (2009) 213-224.

[2] Salvat, Fernandez-Varea, Sempau, Workshop Proceedings, Barcelona, Spain (2006) 281 PP.

[3] Llovet and Galan, American Mineralogist, 88 (2001) 121-130 


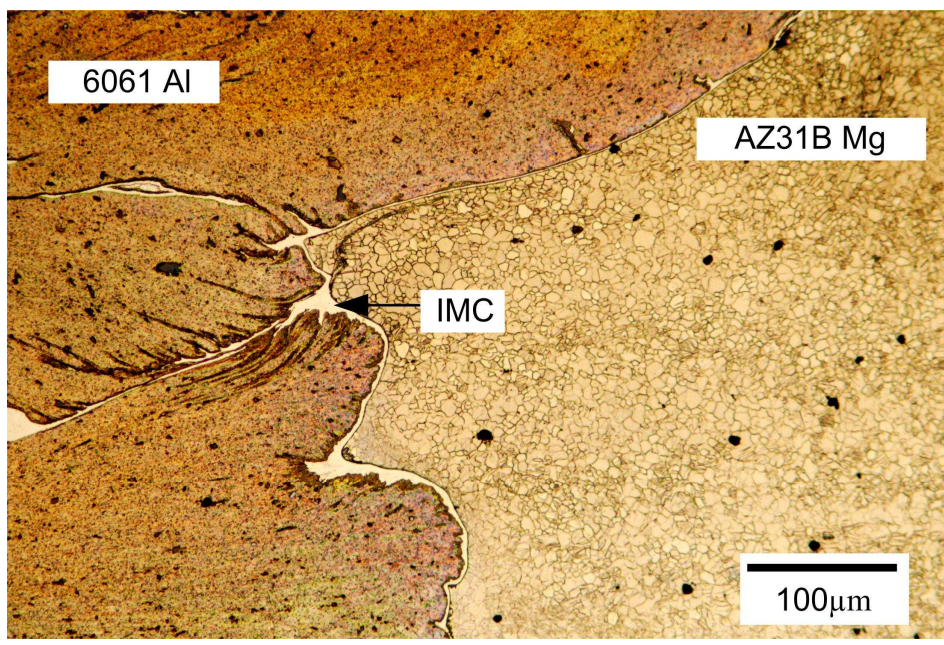

Figure 1: 6061 Al-AZ31B Mg dissimilar FSW Joint

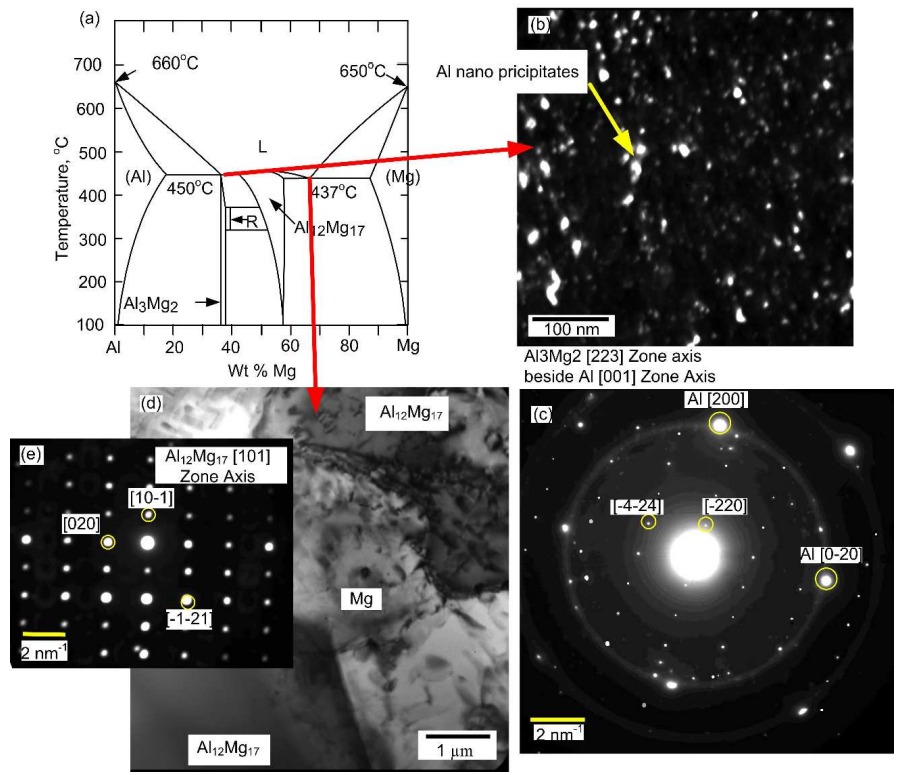

Figure 3: (a) Al-Mg phase diagram (b) and (c) TEM Dark field image and electron diffraction pattern of $\mathrm{Al}_{3} \mathrm{mg}_{2}$ and $\mathrm{Al}$, (d) and (e) Bright field image and electron diffraction pattern of $\mathrm{Al}_{12} \mathrm{Mg}_{17}+\mathrm{Mg}$.

Table 1: Experimentally measured chemical composition of Al3Mg2 IMC and PENEPMA K-ratio

\begin{tabular}{|c|c|c|c|c|c|c|}
\hline ELEM: & $\mathrm{Mg}$ & $\mathrm{Al}$ & $\mathrm{Si}$ & $\mathrm{Fe}$ & $\mathrm{Cu}$ & $\mathrm{Zn}$ \\
\hline$w t \%$ & 40.04 & 63.47 & 0.37 & 0.06 & 0.21 & 0.67 \\
\hline K-Ratio & 0.4134 & 0.4421 & 0.002 & 0.0005 & 0.002 & 0.006 \\
\hline \multirow{6}{*}{ Calculated K-Ratio } & 0.4236 & 0.4598 & - & - & - & - \\
\hline & \multicolumn{6}{|c|}{ Table 2: Calculated amount of SF using PENEP } \\
\hline & \multirow{2}{*}{\multicolumn{2}{|c|}{$\mathrm{Al}_{3} \mathrm{Mg}_{2}$}} & & Al-SF & \multicolumn{2}{|c|}{$1.4 \%$} \\
\hline & & & & Mg-SF & \multicolumn{2}{|c|}{$3 \%$} \\
\hline & \multicolumn{2}{|c|}{6061 Al Std } & & Al-SF & \multirow{2}{*}{\multicolumn{2}{|c|}{$\frac{1.4 \%}{1.7 \%}$}} \\
\hline & \multicolumn{2}{|c|}{ AZ31B Mg Std } & & $\mathrm{Mg}-\mathrm{SF}$ & & \\
\hline
\end{tabular}

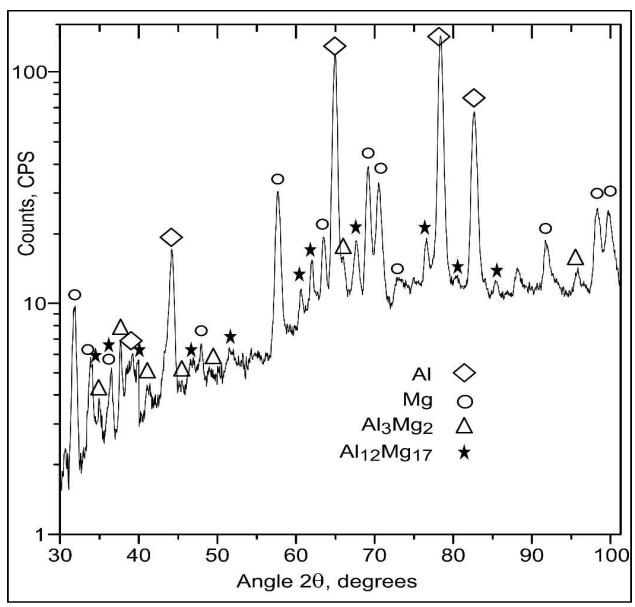

Figure 2: X-ray powder diffraction pattern of Al-Mg dissimilar joints

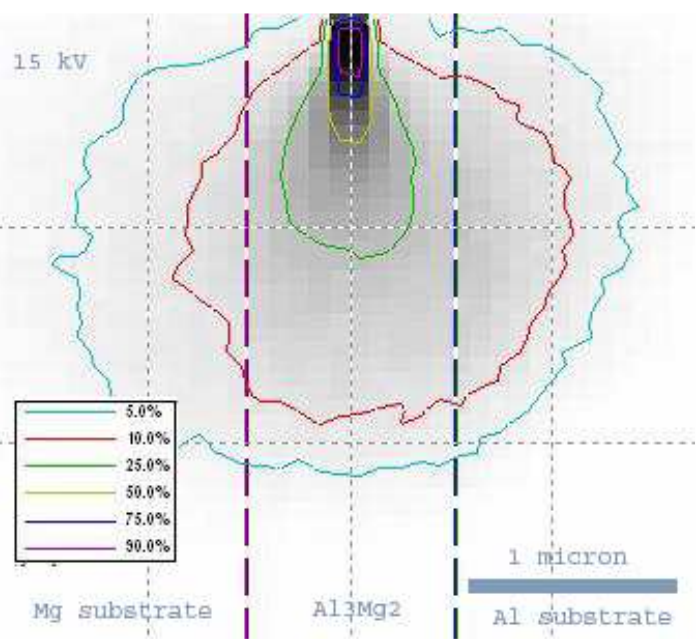

Figure 4: Monte Carlo simulation crosssection of electron scattering/energy levels of the modeled system geometry at $15 \mathrm{kV}$ will be excited down to the $10 \%$ level, and Mg a bit lower. using CASINO. Both $\mathrm{Mg} \mathrm{K} \alpha$ and $\mathrm{Al} \mathrm{K \alpha}$ 